\title{
Bumper Stickers in Jordan: A Structural Analysis
}

Husam Al-Momani, Baker Mohammad Jamil Bani-Khair, Yousef Mohammad Khaled Alshaboul

Hashemite University, Jordan

Corresponding Author: Abdullah Ahmad Jaradat, E-mail: abdjaradat@gmail.com

\section{ARTICLE INFO}

\section{Article history}

Received: June 10, 2017

Accepted: August 05, 2017

Published: August 31, 2017

Volume: 8 Issue: 4

Advance access: August 2017

Conflicts of interest: None

Funding: None

\section{Key words:}

Structural Analysis,

Jordan,

Bumper Stickers

\begin{abstract}
This study has set out to determine the structural patterns of bumper stickers in Jordan. This study is significant since it is the first one to approach bumper stickers structurally. The study has investigated 227 stickers, which can be considered the corpus of stickers in Jordan. The study has found that around $90 \%$ of the stickers are sentences, most of which are simple sentences expressed in the present tense. This combination of the three elements i.e. sentence, declarative and simple is what facilitated the job of drivers to write their opinions, attitudes, beliefs, etc. and is what made it possible for the others i.e., drivers and pedestrians to understand the stickers. The study has also found that imperative and negative imperatives are quite common since the stickers are not addressed to the writer/driver rather to the others so as to inform them about his state, his miserable condition, his opinions, his loyalties, and his vehicle. The stickers are addressed to others to demand certain behaviors from them such as driving wisely, not challenging the sticker writer, respecting him if he is driving a truck or a lorry, etc.
\end{abstract}

\section{INTRODUCTION}

The spread of vehicles has led to the spread of a new genre of discourse which has distinctive features content- and structure-wise. This genre is called bumper stickers since it involves phrases or sentences that are usually written on stickers attached to bumpers. The phrases or sentences that the stickers include are characterized by the following visual features. The first is brevity; stickers include brief statements since there is not sufficient space to write long sentences not to mention paragraphs. The second is that they are large in size so as to be seen and read easily. The third is simplicity so as to be read and understood by all readers.

Generally speaking, drivers consider their cars as moving billboards or venues to express their beliefs, opinions, attitudes, faiths, and orientations, or even sense of humor. Cars are utilized to publicize the driver's affiliation with, or enmity towards, a certain group or person. In other words, stickers represent the driver's reaction towards the current issues in society.

This phenomenon has been widely studied in the west where the focus is mainly on the themes of the stickers which are political in nature and which reflect the driver's alliance with a certain group or his or her attitude towards a certain issue. However, the phenomenon has been rarely studied in the Arab countries in general and in Jordan in specific.

This paper will attempt to investigate the structural patterns of bumper stickers in Jordan. It aims at determining the most repetitive structures of stickers; it tries to discover how the structures of stickers facilitate the process of declaring states, opinions, or attitudes for drivers. The paper will also investigate how the structure of bumper stickers is vital in delivering the message it carries correctly and concisely. The paper will discuss the length of the stickers; whether they are sentences, phrases or words; the most commonly used tense; and how the structure helps covey the messages.

The paper is designed as follows. The methodology of the study is presented in the next section. Section 3 presents the findings of the study. Section 4 provides interpretations and explanations for findings in the previous section. The last section presents the conclusions and recommendations for further studies.

\section{METHODOLOGY}

Bumper stickers are collected and then sorted into their structural and stylistic features. The study adopts the qualitative method; it has collected the highest number of stickers it could reach. The number of stickers studied here is not a sample of the stickers used in Jordan; rather, they nearly represent the exact number of stickers used in Jordan. During the process of collecting and sorting out stickers, the researcher has been forced to leave out instances of repetitions since some stickers were repeated over a number of cars.

The stickers covered in the study are 227, and have been collected during a three-month period from September 2014 to 
the end of November of the same year. The researcher has been aided by the students of the sociolinguistics class he has taught at the Hashemite University during that period. To them the researcher would like to express deep gratitude and appreciation.

The stickers are classified according to the following criteria: 1) sentence vs. non-sentence; 2) sentence types including declarative, imperative or interrogative; 3 ) sentence complexity including simple, compound, or complex sentences; 4) type of non-sentences and 5) the tense including present, past or future. The study will attempt to show how these structures make it easier for drivers to publicize their messages through stickers.

The questions of the study as well as the rationale for these questions are given below.

1. What is the preferable structure of stickers in Jordan?

This is important since bumpers are not big enough for a paragraph or a passage which will not be easily visible by other drivers or passersby. The stickers must be big enough to be read in a second or a fraction of a second.

2. Which type of sentences is the most frequent?

This question touches upon the idea of space and visibility again. It is also related to whether stickers require complete ideas to express or just phrases and symbols.

3. What is the most repeated tense?

This question tries to see whether stickers are treated as facts; hence, the simple present is used or as regular sentences about people's experiences; hence, the past tense is used.

4. How does the structure facilitate message comprehension?

Simple sentences are complete grammatically and semantically, are visible and can be easily read by the other drivers or passersby; hence they are preferred by sticker writers since they do not involve the complexity compound or complex sentences have; let alone their poor visibility.

\section{REVIEW OF LITERATURE}

The paucity or the lack of studies addressing this topic from a structural point of view makes the study of stickers a challenge by itself.

Despite the abundance of studies that have tackled bumper stickers including Belk (1988), Block (2000), Szlemko et al (2008), Stern and Soloman (1992), Chiluwa (2008), Jay Nordlinger (2015), Burt and Simes (2015), Haynsworth (2008), and Norton-Meier (2004) among many, most if not all of these studies have focused on the themes of stickers; their positive or negative consequences on the reader and drivers at the same footing; and how they reflect the social, economic and political issues.

None of the abovementioned studies has focused on the structural patterns of stickers. The paucity of the studies handling this topic is double-edged. First, it makes the idea of conducting the study a challenge since nobody has done this before; second, this makes the study significant due to its being the first in the field.

Only two studies have come across the structure of bumper stickers though they have not specified or determined the structural patterns of the stickers. Das (1991) has investigated the dialogic and argumentative structures of English bumper stickers in Turkey, though he has not talked about the grammar of stickers. He states that one of the common properties of English stickers in Turkey is that these stickers try to build a dialogue with the addressee; this, however, is predictable since stickers are not addressed to the writer or the owner of the car himself; rather, they are addressed to the others whether they are drivers of pedestrians. The stickers are used to show others your identity, nationality, ethnicity, beliefs, opinions, attitudes, etc.

One structural feature that Das (1991) has talked about indirectly is the bipartite structure of bumper stickers. Das has not named this feature; rather, he has talked about it indirectly when he says that most stickers have a dialogic structure. Das says:

The linguistic structures of discourse are important in this argumentative process. The addressee always comes to a conclusion by reading the first utterance. If the addressee accepts the first utterance as the correct one, he or she has to accept the ones that follow. P 71

Das concludes by saying that 'the structure of discourse makes it easier to construct a dialogue' (P74).

Almeda and Bush (2012) talk about bumper stickers as an example of discourse the grammar of which varies widely depending on the needs of the audience and the goals of the writer. They believe that there is not one set of grammar; there is a multiplicity of grammars; each is defined by the context in which it is applied. Accordingly, rules of correct grammar that we know and have studied at schools cannot be applied to stickers. In this sense, they say that a sentence can be a single word, or at most a short fragment. They also say that an analysis of grammar here may include the discussion of color, size, of text, and font.

Apparently, Almeda and Bush have adopted a radical approach in viewing language in context. However, this radical view would not be of any help in this study since this paper tries to classify stickers to grammar rules that we have studied, and which they totally refuse in this context.

Jaradat (2015) studies the themes of bumper stickers in Jordan stating that stickers in Jordan can be viewed as a mirror to the social and economic problems of society. He says that stickers in Jordan are generally speaking not serious; they are funny in nature intended to show the driver's sense of humor. The most common topics are lessons from life, challenging other driver, love, the low economic status of the car, the miserable condition of the driver, and how to treat a car. Interestingly, Jaradat says that the stickers have not tackled any political issue, and they are not serious i.e. they do not carry any biting comment of any collective problem for Jordanians.

Obviously, no study has focused on the grammatical features of bumper stickers; a fact that gives this study some importance.

\section{FINDINGS}

The findings of the study will be presented in sections; each discusses a single criterion. 


\section{Sentences vs. Non-sentences}

As mentioned before, the paper starts by classifying stickers into sentences and non-sentences. This criterion can unveil the preferable structures of stickers for drivers. It has been found that out of 227 stickers covered in this study, 200 are sentences. This number forms $88.1 \%$ of the total number of stickers. Non-sentences on the other hand appears 27 times only forming up $12 \%$ of the number of stickers. Accordingly, one can say that sentences are the preferable structure for stickers in Jordan. Stickers 1 and 2 below are sentences, while stickers 3 and 4 are examples of non-sentences:

It is the destiny of the small one to be bigger/older.

Do not say how much; I bought it through debts.

The scorpion

The brother of night

\section{Sentence Type}

The second goal of the paper is to determine the most common type of sentences used. This section answers the second question of the study. It has been found that the most common type of sentences is the declarative sentence. The number of declarative sentences is 124 out of 200 sentence stickers. This number makes up to $62 \%$ of the total number of sentences and $54.6 \%$ of the total number of stickers. This finding is not unpredictable since declarative sentences are the widely-used type of sentences in both English and Arabic at the same footing. The following are examples of stickers in declarative sentences:

The Porches is at home.

The driver is flammable.

The goal of my life is an offside.

The second common type of sentences is the imperative. The number of imperative stickers is 70 , and this makes up to $35 \%$ of the number of sentences and $30.8 \%$ of the total number of stickers. Most imperative sentences appear as commands or orders addressed by the speaker to the others mainly as warnings so as not to commit any silly misdemeanor that might involve challenging or threatening the driver or the writer of the sticker. Consider the following examples of imperative stickers:

Do not follow me; I am indebted.

Forget about a life like this.

Make space for the big.

The last type of sentence stickers is the interrogative. It is in fact the least in number; 25 to be exact, and these constitute $12.5 \%$ of the number of sentence stickers and $11 \%$ of the total number of stickers. The following are stickers containing interrogatives:

Do you a person who knows a person who knows me?

Is this your reality or is it the consequence of a hit by a shovel?

How do you see my driving?

\section{Non-Sentences}

When it comes to non-sentences, the exact number is 27 , and they form $11.9 \%$ of the total number of stickers. The following are examples of non-sentences; each represents a certain pattern:

The scorpion (NP)

A tank project (The car is intended to be a tank) (NP NP)

A disdained Volkswagon better than an indebted Mercedes(NP not NP)

A Hummer after the diet (NP PP)

The exact frequency and percentage of each type is given in table 1 at the end of the findings section.

\section{Sentence Complexity}

When it comes to sentence complexity, it has been found that most of the sentences in the stickers are simple. The exact number of simple sentences is 102 forming $51 \%$ of the number of sentence stickers and around $45 \%$ of the total number of stickers. The following are examples of sticker of simple sentences:

The ghost is with the madam.

Make space for the big.

It is written on mirrors only for girls.

Compound sentences form the second highest type in this criterion. They are 62 in number and they form $27.3 \%$ of the total number of stickers and $31 \%$ of sentence stickers. The following are examples of stickers of compound sentence:

I talk and the others are in pain.

The sea is salty, and people are running after benefits.

Life is not merciful not people are understanding.

The last group contains complex sentences. This group is the smallest in number. The number of complex sentences is 35 forming $17.5 \%$ of the total number of stickers and 15.4 $\%$ of the total number of sentence stickers. Examples 21, 22 and 23 are examples of complex sentences:

When I grow, I will become a Hummer.

When the big appears in the arena, there will be no enough space.

If you do not like it, you should depilate your eyebrows.

\section{Tense}

This section answers the third question which is, 'what is the most repeated tense?' As expected, the most commonly-used tense in stickers is the present tense; the number of stickers that contain the present tense is 179 making up $78.9 \%$ of the total number of stickers and 89.5 of the total number of sentence stickers. Consider the following stickers in the present tense:

Do not follow me; I am indebted.

The driver is highly flammable.

It is written on the mirrors 'restricted for girls.'

The second most frequent tense is the past tense, though there is a large gap between the stickers in the present tense and those in the past tense. The number of stickers in the past tense is 15 , and these make up to $7.5 \%$ of the total number of stickers and $6.6 \%$ of the number of sentence stickers. The following stickers contain the past tense:

The beautiful peach came after dizziness. (The car)

Had you known about me, you would have cried at me. When I finished building the ship, the sea became dry. 
The tense with the least number is the future tense. Only 5 stickers showed the future tense. This number constitutes $2.2 \%$ of the total number of stickers and $2.5 \%$ of the total number of sentence stickers. The examples below are examples of sticker in the future tense:

When I grow up, I will show you.

By Allah, I will make him a lesson.

If you tell a tongue-tied woman your secret, her tongue will be freed immediately.

\section{DISCUSSION}

In this section, I will attempt to interpret and give explanations for the findings presented in the previous section. This section will be divided according to the divisions followed in the findings section.

\section{Sentence vs. Non-sentences:}

The abundance of sentences in comparison to non-sentences is natural since non-sentences are not sufficient enough to represent or to express what the driver thinks or believes; a sentence is required to achieve this. A non-sentence can be used to name; while sentences are used to describe, interpret, define, comment, etc. Moreover, sentences give complete ideas. This feature of sentences is important in this situation since readers of stickers whether they are drivers or passersby have a very short time to read the sticker, and they may not have another chance to read it again. Consequently, the sticker must be a self-contained sentence that leaves no part unsaid or unmentioned.

\section{Sentence Types}

The abundance of declarative sentences in the corpus reflects the massive distribution of declarative sentences in daily use. Generally speaking declarative sentences are used when the speaker wants to make a statement that contains new information. The drivers are using this type to tell the others about their problems, the lessons they have learned from past experience, the love experiences they have been through, the low economic situation they are going through and the challenges they are facing on a daily basis. Accordingly, drivers are using this type since it is the most informative, the most expressive, and the most direct of the three types. It is the most convenient way to convey the driver's themes.

The relatively high number of stickers containing imperatives is predictable since roads are seen as arenas in which every driver tries to refer to as his territory. Drivers aim through these stickers to prove their rights in doing what they desire roads such as speeding, wrong overtaking, shouting at others, starting horns since they think they are the most skillful, the fastest, and the most powerful. In fact, I can say that they are doing so since they are the foulest and the most reckless.

Interrogative are the least common type of sentences. I guess they are so since they do not involve direct speech to the other drivers. They cannot be used to make a statement

Table 1. Frequency and percentages of the structural patterns

\begin{tabular}{|c|c|c|c|c|}
\hline & Type & Frequency & $\%$ out of the total number & $\%$ out of the same type \\
\hline \multirow[t]{2}{*}{ S vs. NS } & NS & 27 & 11.89 & \\
\hline & $\mathrm{S}$ & 200 & 88.10 & \\
\hline \multirow[t]{4}{*}{ Types of sentence } & Declarative & 124 & 54.1 & 62 \\
\hline & Imperative & 70 & 35 & 35 \\
\hline & Interrogative & 5 & 11 & 2.5 \\
\hline & Exclamatory & 1 & 0.44 & 0.5 \\
\hline \multirow[t]{3}{*}{ Sentence complexity } & Simple & 102 & 44.9 & 51 \\
\hline & Compound & 62 & 27.3 & 31 \\
\hline & Complex & 35 & 15.4 & 17.5 \\
\hline \multirow[t]{5}{*}{ Types of complex sentences } & Time & 6 & 2.6 & 22 \\
\hline & Conditional & 10 & 4.4 & 37 \\
\hline & Cause & 2 & 1.7 & 14.8 \\
\hline & Noun clause & 5 & 2.2 & 18.5 \\
\hline & Adj. clause & 4 & 0.9 & 7 \\
\hline \multirow[t]{3}{*}{ Tense } & Present (R) & 179 & 78.85 & 89.5 \\
\hline & Past (S) & 15 & 6.6 & 7.5 \\
\hline & Future (F) & 5 & 2.2 & 2.5 \\
\hline \multirow[t]{5}{*}{ Types of non-sentences } & NP & 6 & 2.6 & 22.2 \\
\hline & $\mathrm{NP} / \mathrm{NP}$ & 1 & 0.4 & 3.7 \\
\hline & NP not NP & 6 & 2.6 & 22.2 \\
\hline & NP PP & 10 & 4.4 & 37 \\
\hline & Other & 4 & 1.8 & 14.8 \\
\hline
\end{tabular}


about the driver, or to provide a description of the driver's economic situation, or his vehicle, or any other issue related to both. In fact, all the interrogative sentences are simply funny and cannot be taken seriously. Although interrogatives, like imperatives, are addressed to the others; however, they are unlike the imperatives since the driver in case of interrogatives is not stating his absolute power, and his status to rule the road.

\section{Non-Sentences}

One might ask why non-sentences are used in stickers. Two scenarios might be given to answer the question. The first is that some stickers contain nicknames the driver coined for his vehicle, and nicknames do not need sentences to be expressed. Nicknames are nouns that are best expressed as noun phrases.

The second scenario is that some stickers might contain comparisons which will need a bigger space if they are written as a full sentence. In this case drivers will use a smaller font size which will make the process of reading them more difficult. Moreover, writing long sentences in a big font size is a challenge since the bumper will not provide enough space. Consequently, comparison is expressed in the formula 'NP not NP' with the meaning ' $\mathrm{X}$ is better than Y.'

The third group of non-sentences contains two noun phrases that are written in the construct phrase formula. This structure requires that two nouns follow each other immediately without any separating words; the first noun is the head noun while the second helps to identify, modify, or restrict the first noun. The structure is very common in both Standard and Jordanian Arabic.

\section{Sentence Complexity}

This section seeks to explain the various types of sentences i.e. simple, compound, complex in stickers.

Due to the petite space the stickers are written on and to the shortage of time given to other drivers and pedestrians to read the stickers, the stickers need to be written in the biggest size of font. Consequently, the shorter and the simpler the sentence is, the more space is there for a sticker to be written in a bigger font size. This explains the abundance of simple sentences.

The compound sentences used are also very short and they meant to make a comparison between the drivers' cars, economic status, beliefs, with other drivers' cars, economic status, and beliefs. However, the use of compound sentences can also be accounted for by external factors like rhyme, and complexity of meaning.

Finally, the paucity of complex sentences is due to the fact that these sentences are the longest in terms of words. The scarcity of complex sentences can also be due to complex relationships between ideas expressed in these sentences. The subordinate clause usually places a condition on or specifies a certain time, presents a cause for the occurrence of the event in the main clause. Readers need to be aware of these relationships which make complex sentences more difficult to deal with.

\section{Tense}

The high frequency of the present tense can be accounted for by various factors. First, most stickers express the driver's beliefs, attitudes, convictions, and current economic status, in other words, they talk about present or current states or events which require the use of the present tense. These meanings cannot be expressed well unless they are used in the present tense. These themes are states and habituals or repeated events that are usually expressed in the present tense. Second, the present tense is considered the unmarked or the generic tense which is commonly used in generic utterances to express habitual events or reiteration. According to Dahl $(1975,1995)$ when we use generic tense we state that a law or a principle of some sort is in force at a certain time, i.e. we make a nomic statement.

The rarity of the past tense is due to the fact that the past tense is used to talk about past experiences which the driver does not like or hates to talk about like treachery. It seems that drivers like to talk about current issues or lessons they learned the hard way from life than to talk about their past experiences.

The scarcity of the future tense is due to the fact that drivers do not like to talk about future intentions of future events. However, the stickers in the future tense carry the meaning of threatening. The speaker in these stickers is the car. The small car is threatening other cars that it will revenge from big cars when it becomes older or bigger in age and size. This explains the use of the future tense in these stickers.

\section{CONCLUSIONS}

This paper has set out to determine the most repetitive and, as a consequence, the preferable structural patterns of bumper stickers in Jordan.

The study has shown that around $90 \%$ of the stickers are coined in sentences; while non-sentences appeared in only $10 \%$, which shows that the preferable structure for stickers is the sentence. The study has also shown that the declarative sentence type is the most recurring with about $62 \%$, followed with the imperative type with $35 \%$ followed by the interrogative type with $2.5 \%$ and lastly followed by the exclamatory type with $0.5 \%$. When it comes to sentence complexity, the study has found that most sentences are simple 51\%, while compound sentences appeared in $31 \%$ of sentence stickers and complex sentences appeared in $17.5 \%$ of sentence stickers. This finding shows that the simpler the sticker is, the better it in terms in space, visibility, and comprehension.

The study has also found that the present tense is the most recurrent tense in the stickers with around $90 \%$ of sentence stickers, followed by the past tense with $7.5 \%$, which is followed by the future tense with $2.5 \%$. The extreme abundance of the present tense in stickers is due to its being the generic tense and the one that is used to express habitual events and current states.

The findings of the study indicate that stickers in general follow a basic rule that can be named as the simpler, the better. Most stickers are sentences to be able to express a proposition fully. Most sentences are simple since simple sentences are shorter so that the bumper will fit them. Moreover, simple sentences are easier to analyze and understand. 
The present tense is the most frequent since it is the generic tense and the tense that does not involve any distance from the utterance time.

Due to its being the first study about the structure of stickers, this research provides a framework for further explorations of the structure of bumper stickers. Undoubtedly, the findings of the study will be of great significance for future research about stickers in other regions in the Arab world and in the west.

What is now needed is a comparative study between stickers in Jordan and other Arab countries or the west. Furthermore, it would be interesting to explore the relationship between bumper stickers and some social factor such age, gender, education, occupation and car model.

\section{REFERENCES}

Almeda, Cheryl and Jonathan Bush (2012). The Grammar of Context: Breakfast, Bumper Stickers, and Beyond. Language Arts Journal of Michigan. Vol. 27, Issue 2, PP

Belk, Russell W. (1988). Possessions and the Extended Self. Journal of Historical Research in Marketing. Vol. 7, Issue 2, PP 184-207.

Block, Linda-Renee, (2000). Mobile Discourse: Political Bumper Stickers as a Communication Event in Isreal. Journal of Communication. Vol. 50, No. 2, pp 48-76.

Burt, Richard and Demitri K. Simes, (2015). Foreign Policy by Bumper Stickers. The National Interest. September/ October Issue. New York.

Chiluwa, Innocent, (2008). Religious Vehicle Stickers in Nigeria: A Discourse of Identity, Faith and Social Vision. Discourse and Communication. Vol. 2, No. 4. PP 371-87.
Dahl, Östen, (1975). On Generics. In E.L.Keenan (ed.) Formal Semantics of Natural Language. PP 99-111. Cambridge: Cambridge University Press.

(1995). The Marking of Episodic/Generic Distinction in Tense-Aspect Systems. In Carlson, Greg, N. \& Pelletier, Francis Jeffry. (eds.) The Generic Book. Chicago: University of Chicago Press.

Das, D. A. (1991). Dialogic and Argumentative Structures of Bumper Stickers. In Mak Karawan and Andrew U. Frank (eds.) Cognitive and Linguistic Aspects of Geographic Space. Kluwer Academic Publishing.

Haynsworth, Leslie, (2008). My Volvo, My Self: The (Largely Unintended) Existential Implications of Bumper Stickers. Fourth Genre. Vol. 10, No.1. pp 21-34.

Jaradat, A (2015). Content-Based Analysis of Bumper Stickers in Jordan. Sociolinguistic Studies: under-review.

Nordlinger, Jay, (2015). Stick It to 'em: A World of Bumper Stickers. National Review. Vol. LXVII, No. 15, pp 26-27. New York.

Norton-Meier, Lori A, (2004). The Bumper Sticker Curriculum: Learning from Words on the Backs of Cars. Journal of Adolescent and Adult Literacy. Vol. 48, No.3. PP 260-63.

Stern, B. B, and Soloman, M. R. (1992). "Have You Kissed Your Professor Today?": Bumper Stickers and Consumer Self Statements. Advances in Consumer Research, 19, PP 169-173.

Szlemko, W., Jacob A. Benfield, Paul A. Bell, Jerry L. Deffenbacher and Lucy Troup, (2008). Territorial Markings as a Predicator of Driver Aggression and Road Rage. Journal of Applied Social psychology, Vol. 38, No. 6, PP 1664-88. 